\title{
Knowledge and Attitude towards Prevention and Management of Hypertension in Jatinangor Sub-district
}

\author{
Kartika Malahayati, ${ }^{1}$ Rudi Supriyadi, ${ }^{2}$ Herri S. Sastramihardja ${ }^{3}$ \\ ${ }^{1}$ Faculty of Medicine, Universitas Padjadjaran, ${ }^{2}$ Department of Internal Medicine Faculty of \\ Medicine Universitas Padjadjaran/Dr. Hasan Sadikin General Hospital Bandung ${ }^{3}$ Department of \\ Pharmacology and Therapy Faculty of Medicine Universitas Padjadjaran
}

\begin{abstract}
Background: There is an increase in prevalence of hypertension all over the world as well as Indonesia. Hypertension affects almost all body organs and systems. Hypertension prevention and management are influenced by knowledge and attitude towards the disease. The aim of this study was to assess knowledge and attitude towards prevention and management of hypertension.

Methods: This was a descriptive study with cross-sectional approach conducted in Jatinangor sub-district in 2013. Sample sizes were determined based on proportion of the case in population and precision estimates (95\% confidence intervals). One hundred twenty respondents aged 18-60 year-old were selected from population using stratified random sampling method. Hypertensions knowledge and attitude were assessed using validated questioner as the scale measurement. Frequency of knowledge level was presented as three ordinal categories; good, moderate, and poor. Attitude of hypertension was presented as frequency in two categories; relatively positive and relatively negative.

Results: Out of 120 respondents administered the questioner, $42.50 \%$ had good knowledge; $41.67 \%$ had moderate knowledge; $15.83 \%$ had poor knowledge related to hypertension prevention and $21.67 \%$ had good knowledge; $19.17 \%$ had moderate knowledge; $59.17 \%$ had poor knowledge related to management of hypertension. Hypertension attitude of respondents were $60.83 \%$ relatively positive in topics of hypertension prevention and $39.17 \%$ in topics of hypertension management.

Conclusions: Respondents are knowledgeable about hypertension prevention but are less knowledgeable about its management. Respondents have relatively positive attitudes towards hypertension prevention. In the other hand, respondents have more relatively negative attitudes towards its management. [AM].2016;3(2):222-9]
\end{abstract}

Keywords: Attitude, hypertensions, knowledge, prevention, treatment.

\section{Introduction}

According to World Health Organization (WHO), in 2008, hypertension had prevalence of $40 \%$ in worldwide adult population. ${ }^{1}$ Furthermore, the number of adults with hypertension in 2025 was predicted to increase $60 \%$ to a total of 1.56 billion adults. ${ }^{2}$ The other studies report that hypertension is one of the leading causes of premature death worldwide, accounting 7.5 million deaths, about or $12.8 \%$ of the total of all annual deaths. This accounts for 57 million Disability Adjusted Life Year (DALYs) or $3.7 \%$ of total DALYs. ${ }^{1,3,4}$

Hypertension is a common disease in Indonesia. The disease still occupies the seventh position of the top ten outpatients in hospitals in 2010. The incidence of hypertension reached 80,615 cases in that year. ${ }^{5}$ According to Riset Kesehatan Dasar (Riskesdas) Indonesia 2007, there are at least $31.7 \%$ of the total population, equivalent to 74 million people in Indonesia have hypertension. ${ }^{6}$ In addition, hypertension is often referred to the silent killer due to the character of the disease that does not cause symptoms until complication appeared, such as cerebrovascular disease, ischemic heart disease, heart failure and kidney failure. ${ }^{3,4}$ The high rates of hypertension and the dangers posed by its complications make hypertension as one of the major health burden in Indonesia.

In this context, a strategy to improve the health level of Indonesians should include the prevention and management of hypertension.

Correspondence: Kartika Malahayati, Faculty of Medicine, Universitas Padjadjaran, Jalan Raya Bandung-Sumedang Km.21, Jatinangor, Sumedang, Indonesia, Phone: +62 85279085993 Email: kartika.malahayati@gmail.com 
Prevention and treatment of diseases are form of health behavior that is a normal response to a health stimulus. There are three areas of health behavior, namely knowledge, attitude, and practice. First is to find out the stimulus, and then gives a response in the form of attitude, followed by practice and the application.

The purpose of this study was to assess hypertension knowledge and attitude of people who lived in Jatinangor sub-district related to prevention and treatment of the disease.

\section{Methods}

This was a descriptive study with a crosssectional approach. This study had been approved by Health Research Ethics Committee with a letter numbered 212 \UN6. C2.1.2 \KEPK $\backslash 2013$ to be conducted between August-September 2013 in Jatinangor subdistrict.

Hypertensions knowledge and attitude was assessed using questioner as the scale measurement. The final scale had 22 items with four sub-dimensions of preventionknowledge, prevention-attitude, managementknowledge, and management-attitude. In order to determine qualification measured by scale, validity and reliability of the questioner was pilot tested to 30 randomly-selected participants out of the respondents of the study.

Sample size was determined based on proportion of the case in the population and precision estimates $(95 \%$ confidence intervals). After being stratified based on villages, respondents were selected from population using random sampling method. The inclusion criteria for respondent of this study are aged between 18-60 year-old and lived in Jatinangor. One hundred twenty respondents were involved in this study.

Statistical Product and Service Solution (SPSS) version 16.0 for Windows and Microsoft Excel 2010 were used for data analysis. From the analysis, knowledge of hypertension was

Table 1 The Distribution of The Study Group According to Various Demographic and Medical Characteristics of Respondents

\begin{tabular}{lcc}
\hline \multicolumn{1}{c}{ Characteristics of respondents } & Frequency $\mathbf{~ ( n ~ = ~ 1 2 0 ) ~}$ & Percentage (\%) \\
\hline Gender & 51 & 42.50 \\
Male & 69 & 57.50 \\
Female & & \\
Age group (years old) & 41 & 34.17 \\
18-30 & 27 & 22.50 \\
$30-40$ & 20 & 16.67 \\
$40-50$ & 32 & 26.67 \\
$50-60$ & & \\
Education level & 2 & 1.7 \\
No Formal education & 15 & 12.5 \\
Elementary school & 47 & 39.2 \\
Junior high school & 50 & 41.7 \\
Senior high school & 6 & 5.0 \\
College & & \\
Personal history of hypertension & 101 & 84.17 \\
Absent & 19 & 15.83 \\
Present & & \\
Family history of hypertension & 93 & 77.50 \\
Absent & 27 & 22.50 \\
Present & & \\
\hline
\end{tabular}


Table 2 Knowledge of Hypertension Prevention Based on Characteristics of Respondents

\begin{tabular}{lcccccc}
\hline & \multicolumn{6}{c}{ Knowledge of hypertension prevention } \\
\cline { 2 - 7 } Characteristics of respondents & \multicolumn{2}{c}{ Good } & \multicolumn{2}{c}{ Moderate } & \multicolumn{3}{c}{ Poor } \\
\cline { 2 - 7 } & $\mathbf{n}$ & $\mathbf{9}$ & $\mathbf{n}$ & $\mathbf{\%}$ & $\mathbf{n}$ & $\mathbf{\%}$ \\
\hline Gender & 22 & 43.14 & 22 & 43.14 & 7 & 13.73 \\
Male & 29 & 42.03 & 28 & 40.58 & 12 & 17.39 \\
Female & & & & & & \\
Age group (years old) & 15 & 36.59 & 16 & 39.02 & 10 & 24.39 \\
18-30 & 12 & 44.44 & 12 & 44.44 & 3 & 11.11 \\
$30-40$ & 4 & 20.00 & 11 & 55.00 & 5 & 25.00 \\
40-50 & 20 & 62.50 & 11 & 34.38 & 1 & 3.13 \\
50-60 & & & & & & \\
Education level & 1 & 50.00 & 1 & 50.00 & 0 & 0.00 \\
No Formal education & 9 & 60.00 & 5 & 33.33 & 1 & 6.67 \\
Elementary school & 21 & 44.68 & 20 & 42.55 & 6 & 12.77 \\
Junior high school & 20 & 40.00 & 22 & 44.00 & 8 & 16.00 \\
Senior high school & 0 & 0.00 & 2 & 33.33 & 4 & 66.67 \\
College & & & & & & \\
Personal history of hypertension & & 36.84 & 9 & 47.37 & 3 & 15.79 \\
Present & 7 & 43.56 & 41 & 40.59 & 16 & 15.84 \\
Absent & 44 & & & & & \\
Family history of hypertension & & 44.44 & 11 & 40.74 & 4 & 14.81 \\
Present & 12 & 41.94 & 39 & 41.94 & 15 & 16.13 \\
Absent & 39 & & & & &
\end{tabular}

divided into two sub-dimension, knowledge to prevention and knowledge to management of hypertension. The knowledge outcome measurement was the percentage of the accumulation score. This score then was put into three ordinal categories, good, moderate, and poor. If the total right answer was 76$100 \%$, then knowledge of respondents would be categorized as good. If the total right answer was $56-75 \%$, interpretation of respondents' knowledge about hypertension would be categorized as moderate. If the total right answer was $\leq 55 \%$, respondents' knowledge about hypertension was classified as poor.

Attitude of hypertension was divided into two sub-dimension, attitude to prevention and attitude to management of hypertension. This variable was presented using ordinal measurement scale. Attitude measurement in this study used a Likert scale, where each response to an attitude questionnaire has a composition degree from very negative to very positive. Results of Likert Scale Model answers were categorized in two categories, positive attitude and negative attitude. To be analyzed, the results were expressed in units of standard deviation of all respondents using a score-T, follows:

$T=50+10\left[\frac{X-\bar{X}}{s}\right]$

Description:

$\mathrm{X}=$ score of respondents on a scale of attitude to be converted into a score-T

$=$ the mean score of all respondents

$\mathrm{s}=$ standard deviation score group

Respondents' attitude towards prevention were relatively positive when the T-score is greater than the mean-T, while the relatively negative attitude were categorized when the $\mathrm{T}$-score less than or equal to the mean-T. 
Table 3 Knowledge of Hypertension Management Based on Characteristics of Respondents

\begin{tabular}{|c|c|c|c|c|c|c|}
\hline \multirow{3}{*}{ Characteristics of respondents } & \multicolumn{6}{|c|}{ Knowledge of hypertension management } \\
\hline & \multicolumn{2}{|c|}{ Good } & \multicolumn{2}{|c|}{ Moderate } & \multicolumn{2}{|c|}{ Poor } \\
\hline & $\mathbf{n}$ & $\%$ & $\mathbf{n}$ & $\%$ & $\mathbf{n}$ & $\%$ \\
\hline \multicolumn{7}{|l|}{ Gender } \\
\hline Male & 14 & 27.45 & 8 & 15.69 & 29 & 56.86 \\
\hline Female & 12 & 17.39 & 15 & 21.74 & 42 & 60.87 \\
\hline \multicolumn{7}{|l|}{ Age group (years old) } \\
\hline $18-30$ & 3 & 7.32 & 9 & 21.95 & 29 & 70.73 \\
\hline $30-40$ & 5 & 18.52 & 6 & 22.22 & 16 & 59.26 \\
\hline $40-50$ & 4 & 20.00 & 2 & 10.00 & 14 & 70.00 \\
\hline $50-60$ & 14 & 43.75 & 6 & 18.75 & 12 & 37.50 \\
\hline \multicolumn{7}{|l|}{ Education level } \\
\hline No Formal education & 2 & 100.0 & 0 & 0.00 & 0 & 0.00 \\
\hline Elementary school & 5 & 33.33 & 3 & 20.00 & 7 & 46.67 \\
\hline Junior high school & 12 & 25.53 & 9 & 19.15 & 26 & 55.32 \\
\hline Senior high school & 6 & 12.00 & 10 & 20.00 & 34 & 68.00 \\
\hline College & 1 & 16.67 & 1 & 16.67 & 4 & 66.67 \\
\hline \multicolumn{7}{|l|}{ Personal history of hypertension } \\
\hline Present & 7 & 36.84 & 6 & 31.58 & 6 & 31.58 \\
\hline Absent & 19 & 18.81 & 17 & 16.83 & 65 & 64.36 \\
\hline \multicolumn{7}{|l|}{ Family history of hypertension } \\
\hline Present & 8 & 29.63 & 7 & 25.93 & 12 & 44.44 \\
\hline Absent & 18 & 19.35 & 16 & 17.20 & 59 & 63.44 \\
\hline
\end{tabular}

\section{Results}

One hundred twenty respondents were included in this study. Of these, $57.5 \%$ were female. The mean age of the respondents was 37.63 years. A personal history of hypertension was observed in $15.8 \%$ and family history in $22.5 \%$ respondents.

Out of 120 respondents administered the questioner, $42.50 \%$ had good knowledge related to prevention of hypertension and $21.67 \%$ had good knowledge related to management of hypertension. About $41.67 \%$ and $19.17 \%$ had a moderate knowledge on prevention and management of hypertension.

Forty percent respondents knew that hypertension is a disease related to the high blood pressure; $64.17 \%$ respondents correctly answered the normal value of human blood pressure. Most of respondents were knowledgeable about prevention of hypertension, accounting $97.5 \%$ respondents believed hypertension can be prevented; $90 \%$ respondents knew that doing some exercise can prevent the hypertension; averagely $78.3 \%$ respondents agreed low salt diet and low fat diet is a good prevention of the disease.

About $59.17 \%$ respondents had poor knowledge about management of hypertension. Although 93.33\% respondents believed that hypertension treatment is very important, only $20.83 \%$ respondents knew that hypertension treatment should be done over a lifetime. When respondents were asked for more specific question related to the management of hypertension, $72.5 \%$ respondents correctly answered that hypertension patient need to consume antihypertensive medicines and 40.83\% knew that non-pharmaceutical management is also important to increase hypertensive patients' health.

Results of hypertension attitude were 
Table 4 Attitude of Hypertension Prevention Based on Characteristics of Respondents

\begin{tabular}{lcccc}
\hline \multirow{2}{*}{ Characteristics of respondents } & \multicolumn{4}{c}{ Attitude of hypertension prevention } \\
\cline { 2 - 5 } & \multicolumn{2}{c}{ Relatively positive } & Relatively negative \\
\cline { 2 - 5 } & $\mathbf{n}$ & $\mathbf{N}$ & $\mathbf{0}$ \\
\hline Gender & 31 & 60.78 & 20 & 60.78 \\
Male & 42 & 60.87 & 27 & 60.87 \\
Female & & & & \\
Age group (years old) & 32 & 78.05 & 9 & 78.05 \\
18-30 & 16 & 59.26 & 11 & 59.26 \\
$30-40$ & 14 & 70.00 & 6 & 70.00 \\
40-50 & 11 & 34.38 & 21 & 34.38 \\
50-60 & & & & \\
Education level & 2 & 100.00 & 0 & 100.00 \\
No Formal education & 3 & 20.00 & 12 & 20.00 \\
Elementary school & 25 & 53.19 & 22 & 53.19 \\
Junior high school & 38 & 76.00 & 12 & 76.00 \\
Senior high school & 5 & 83.33 & 1 & 83.33 \\
College & & & & \\
Personal history of hypertension & 13 & 68.42 & 6 & 68.42 \\
Present & 60 & 59.41 & 41 & 59.41 \\
Absent & & & & \\
Family history of hypertension & 19 & 70.37 & 8 & 70.37 \\
Present & 54 & 58.06 & 39 & 58.06 \\
Absent & & & &
\end{tabular}

expressed in units of standard deviation of all respondents using score-T. Mean-T for attitudes towards hypertension prevention was 49.89 whereas mean- $T$ for attitudes towards hypertension management was 50.00.

From the analysis, it was known that $60.83 \%$ respondents had relatively positive attitude towards prevention of hypertension; $37.17 \%$ respondents had relatively negative attitude towards hypertension. This value was much bigger than attitude value of hypertension management; only $37.50 \%$ respondents were categorized as having a relatively positive attitude. Sixty two percent respondents had a relatively negative attitude, primarily on adherence therapy patients have to follow and strict lifestyle changes.

\section{Discussions}

Death and disability that occurs in hypertensive patients was mostly caused by its complications, such as cerebrovascular disease, ischemic heart disease, heart failure and kidney failure. Hypertension caused $54 \%$ mortality of stroke patients and $47 \%$ of ischemic heart disease deaths. In addition, hypertension is called as silent killer due to its character that will not cause symptoms until complication appear. ${ }^{3,4}$ A lack of knowledge about hypertension negatively influences patients' awareness and behaviors, and is a major obstacle in controlling the disease. ${ }^{7,8}$

Out of 120 respondents, 19 respondents $(15.83 \%)$ had history of hypertension. This number was a little bit higher than hypertension prevalence in Jatinangor subdistrict in 2012 which is $9.61 \%{ }^{9}$

This study result shows that respondents were knowledgeable about prevention of hypertension, but were less knowledgeable about treatment and management of the disease. Out of 120 respondents administered 
Table 5 Attitude of Hypertension Management Based on Characteristic of Respondents

\begin{tabular}{lcccc}
\hline \multirow{2}{*}{ Characteristics of respondents } & \multicolumn{3}{c}{ Attitude of hypertension management } \\
\cline { 2 - 5 } & \multicolumn{2}{c}{ Relatively positive } & Relatively negative \\
\cline { 2 - 5 } Gender & $\mathbf{n}$ & \% & N & \% \\
Male & 17 & 33.33 & 34 & 66.67 \\
Female & 28 & 40.58 & 41 & 59.42 \\
Age group (years old) & & & & \\
18-30 & 15 & 36.59 & 26 & 63.41 \\
$30-40$ & 13 & 48.15 & 14 & 51.85 \\
40-50 & 8 & 40.00 & 12 & 60.00 \\
50-60 & 9 & 28.13 & 23 & 71.88 \\
Education level & & & & \\
No Formal education & 0 & 0.00 & 2 & 100.00 \\
Elementary school & 4 & 26.67 & 11 & 73.33 \\
Junior high school & 19 & 40.43 & 28 & 59.57 \\
Senior high school & 20 & 40.00 & 30 & 60.00 \\
College & 2 & 33.33 & 4 & 66.67 \\
Personal history of hypertension & & & & \\
Present & 6 & 31.58 & 13 & 68.42 \\
Absent & 39 & 38.61 & 62 & 61.39 \\
Family history of hypertension & & & & \\
Present & 8 & 29.63 & 19 & 70.37 \\
Absent & 37 & 39.78 & 56 & 60.22 \\
\hline
\end{tabular}

the questioner, $42.50 \%$ had good knowledge related to prevention of hypertension and $21.67 \%$ had good knowledge related to management of hypertension. This result contradicted to some other studies stated that people, especially in urban and sub-urban area, had tendency to have good knowledge of hypertension prevention as well as hypertension management.,10

Generally, there were many views about definition of hypertension; about $40 \%$ of our respondents knew hypertension indicated by high blood pressure. Interestingly, there was a commonly held notion in population that hypertension might be indicated by excessive worries, thinking or stress (55\% respondents). This was contrary to another similar study denying the presence of that notion in the population. From study conducted by Iyalomhe in sub-urban population, majority of population (61\%) knew exactly about definition of hypertension. ${ }^{7}$

Based on age, the majority percentages of respondents who had good knowledge of hypertension prevention are on age $>40$ years, which is as much as $54 \%$. However, for knowledge of hypertension management there was a tendency that the younger the age, the higher the knowledge. This trend contradicted to the theory of knowledge formation. Age is one factor that affects the formation of knowledge, the older the age of a person, the more constructive he is in using the coping problems encountered. ${ }^{11}$

There was no compelling difference in level of knowledge of hypertension prevention gratified based on respondent's educational background. Yet, there were some inclinations in level of hypertension management knowledge. The results of this study suggested that the lower educational level of respondents, the higher level of knowledge they must have. Based on further observation, it is known that most of respondents gathered the information about hypertension not from formal educational institution, but from 
the clinic of family health care attendance. This inclination also could be caused by the limitation of educational background distribution in respondents' variables.

Hypertension attitude of respondents were relatively positive in topics of hypertension prevention, but more negative in the topics of management of hypertension. This is similar to another study conducted by Lukoschek which stated that people have inclination to have more negative attitude towards management of hypertension though this inclination is influenced by races and socio-demographic factors. ${ }^{12}$

Seventy percent respondents who had personal history of hypertension strongly agreed that hypertension should be prevented. In contrast, when attitude towards management of hypertension were measured, only $29.63 \%$ of these respondents agreed to the lifestyle change as the treatment of hypertension. Some studies have reported that there is a strong correlation between personal histories of hypertension to the attitude of respondents. ${ }^{7,8}$ Oliveria et al..$^{10}$ suggested those people who have history of hypertension tend to give positive response towards both prevention and management of the disease. This difference might be happened because respondents of this study had different concept of hypertension treatment. Respondents had inclination to answer that hypertension only have to be treated until patients are cured. Unfortunately, until now, there is no curative treatment to cure hypertension. The treatments available nowadays are only able to control blood pressure and to prevent further complication of hypertension. ${ }^{3}$

This study is limited due to the ability of researcher for the first time to do research so there were still many shortcomings in data collecting, processing, interpretation and writing results of the research. Design used in this study was descriptive, so it was only able to describe phenomenon without the ability to count the significance of variables for broader results. In addition, although questioner used in this study has been validated, there were still some probabilities of informational bias because questioner consisted of two different scales, so itcould confuse the respondents who filled it.

In conclusion, this study results suggest that respondents have good knowledge about the prevention of hypertension, but are less knowledgeable about the treatment of the disease. Hypertension attitude of the respondents are relatively positive in the topics of hypertension prevention. On the other hand, respondents have much more negative in the topics of management of hypertension.

This study suggested that it is better that the government together with all health care provider paying more attention in controlling hypertension by increasing people's knowledge and awareness towards the disease. It is also important to conduct further analytical research to correct this study's limitations and broaden the scope of research to result a better comprehension of hypertension knowledge and attitude.

\section{References}

1. WHO. Global status report on noncommunicable diseases. Geneva: WHO Press; 2010.

2. Chobanian AV, Bakris GL, Black HR, Cushman WC, Green LA, IzzoJL, etal. Seventh report of the joint national committee on prevention, detection, evaluation, and treatment of high blood pressure. Hypertension. 2003;42(6):1206-52.

3. Whitworth JA, WHO, ISH. 2003 World Helath Organization (WHO)/International Society of Hypertension (ISH) statement on management of hypertension. J Hypertens. 2003;21(11):1983-92.

4. Lawes CMM, Hoorn SV, Rodgers A. Global burden of blood-pressure-related disease, 2001. Lancet. 2008;371(9623):1513-8.

5. Kementrian Kesehatan Republik Indonesia. Profil kesehatan Indonesia tahun 2011. Jakarta: Kementrian Kesehatan Republik Indonesia; 2012.

6. Badan Penelitian dan Pengebangan Kesehatan Kementrian Kesehatan Indonesia. Riset kesehatan dasar Indonesia 2007. Jakarta: Kemenkes RI; 2010.

7. Iyalomhe GBS, Iyalomhe SI. Hypertensionrelated knowledge, attitudes and life-style practices among hypertensive patients in a sub-urban Nigerian community. J Public Health Epidemiol. 2010;2(4):71-7.

8. Buendía J. Attitudes, knowledge and beliefs of patient about anti-hypertensive drugs. Biomedica. 2012;32(4):578-84.

9. Dinas Kesehatan Kab. Sumedang. Profil Puskesmas DTP Jatinangor tahun 2012. Jatinangor: Dinas Kesehatan Kab. Sumedang. 2013.

10. Oliveria SA, Chen RS, McCarthy BD, Davis CC, Hill MN. Hypertension knowledge, awareness, and attitudes in a hypertensive population. J Gen Intern Med. 2005;20(3):219-25. 
11. Jha N, Bajracharya O, Shankar PR. Knowledge, attitude and practice towards medicines among school teachers in Lalitpur district, Nepal before and after an educational intervention. BMC Public Health. 2013;13:652.
12. Lukoschek P. African americans' beliefs and attitudes regarding hypertension and its treatment: a qualitative study. J Health Care Poor Underserved. 2003;14(4):56687. 